\title{
Histologia das glândulas salivares dos Limacoidea e Milacidae (Gastropoda, Pulmonata)
}

\author{
Ana Maria Leal-Zanchet \\ Laboratório de Histologia, Centro de Ciências da Saúde, Universidade do Vale do Rio dos Sinos. 93022-000 São Leopoldo, \\ Rio Grande do Sul, Brasil. E-mail: zanchet@bios.unisinos.br
}

\begin{abstract}
Histology of the salivary glands of the Limacoidea and Milacidae (Gastropoda, Pulmonata). The histology of the salivary glands of six species of Limacoidea, Boettgerilla pallens Simroth, 1912, Deroceras laeve (Müller, 1774), Deroceras reticulatum (Müller, 1774), Deroceras rodnae Grossu \& Lupu, 1965, Malacolimax tenellus (Müller, 1774) and Lehmannia marginata (Müller, 1774), and a species of Milacidae, Tandonia budapestensis (Hazay, 1881) is comparatively described herein. In the glandular parenchyme four to five secretory cell types are distinguished and characterised, besides a cell type which is probably undifferentiated. The secretory cell types are classified into two groups, mucous and serous cells. Two types of mucous cells and two to three types of serous cells are distinguished. The salivary glands of the herein studied Limacoidea and Milacidae show a duct system composed of intralobular, interlobular and main ducts, each one presenting a characteristic type of epithelial lining. The results are comparatively discussed with the data available in the literature, in order to verify the correspondence between the different cell types described for other Pulmonata.
\end{abstract}

KEY WORDS. Excretory ducts, secretory cells, Stylommatophora.

Nos gastrópodes pulmonados, as glândulas salivares tiveram sua histologia e/ou ultraestrutura descritas para poucas espécies, podendo-se mencionar Arion ater (Linnaeus, 1758) (Moya et al. 1992), Deroceras reticulatum (WALKER 1970), Eobania vermiculata (Müller, 1774) (BANI 1964), Helix aspersa Müller, 1774 (BlaIN 1957, Moreno et al. 1982, Charrier 1988), Limax maximus Linnaeus, 1758 (Beltz \& Gelperin 1979), Lymnaea stagnalis Linnaeus, 1758 (BoER et al. 1967) e Phyllocaulis soleiformis (Orbigny, 1835) (Leal-Zanchet et al. 1991), dentre outros. Uma revisão dos estudos histológicos e ultraestruturais realizados sobre a estrutura das glândulas salivares dos gastrópodes pode ser encontrada em Hyman (1967), LeaL-Zanchet et al. (1991) e Luchtel et al. (1997). Esses estudos têm se concentrado em espécies isoladas, não havendo estudos comparativos sobre a constituição das glândulas salivares em espécies filogeneticamente próximas, como, por exemplo, de uma mesma família ou superfamília. Notando a diversidade da organização celular das glândulas salivares dos pulmonados, LuchTel et al. (1997) sugerem que os estudos estendam-se a um maior número de espécies de pulmonados.

No presente trabalho, descreve-se comparativamente a histologia da glândula salivar de seis espécies de Limacoidea e de uma espécie de Milacidae, caracterizando-se os tipos de células secretoras e o epitélio de revestimento dos ductos excretores.

\section{MATERIAL E MÉTODOS}

Espécimes de Boettgerilla pallens Simroth, 1912, Malacolimax tenellus (Müller, 1774), Lehmannia marginata (Müller, 1774), Deroceras laeve (Müller, 1774), Deroceras reticulatum (Müller, 1774), Deroceras rodnae Grossu \& Lupu, 1965 e Tandonia budapestensis (Hazay, 1881) foram coletados nas proximidades de Tübingen, Baden-Württemberg, Alemanha, e mantidos em sala climatizada a $15^{\circ} \mathrm{C}$ (Leal-Zanchet 1998).

Para análise da anatomia microscópica e histologia, os exemplares foram processados, conforme descrito em LEALZANCHET (1998), para inclusão em paraplasto. Cortes seriados transversais e sagitais, de $6 \mathrm{~mm}$ de espessura, foram corados com hematoxilina/eosina ou com os tricrômicos de Masson/ Goldner e Azan/Heidenhain (RomeIs 1989).

Para detecção de mucopolissacarídeos e proteína, material adicional incluído em paraplasto foi submetido às seguintes reações histoquímicas: ácido periódico/Schiff (PAS) (НотchкISS apud PeARSE 1968) com amilase como controle, alcian blue 8GS pH 2,5 (SteEdman apud Romeis 1989), alcian blue 8GS pH 1,0 (Lev \& Spicer apud Romeis 1989), carmim (Best apud Pearse 1968), azul de bromofenol (Bonhag apud Pearse 1968) e tetrazonium (Bonhag apud Pearse 1968).

Para inclusão em histo-resina, os espécimes foram processados conforme descrito em LeAL-Zanchet (1998) e cortes de 


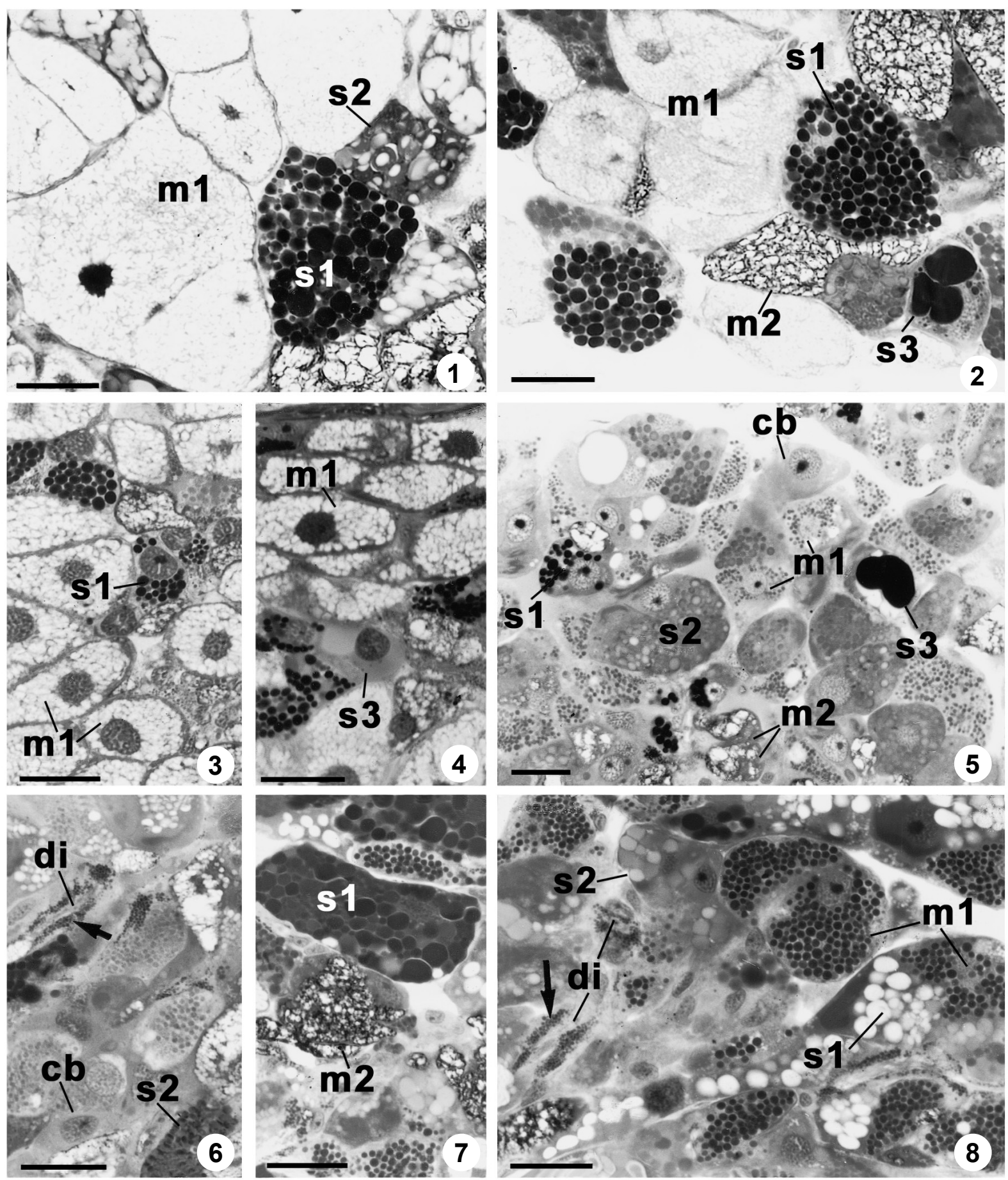

Figuras 1-8. Glândulas salivares em inclusão: histo-resina e coloração: azul de metileno/fucsina básica. (1-2) Boetgerilla pallens: observamse as abundantes células mucosas do tipo I ( $\mathrm{m} 1)$, além de células mucosas do tipo II (m2) e células serosas dos tipos I (s1), II (s2) e III (s3); (3-4) Tandonia budapestensis: observam-se as abundantes células mucosas do tipo I ( $\mathrm{m} 1$ ), bem como células serosas dos tipos I ( $\mathrm{s} 1$ ) e III (s3); (5) Lehmannia marginata: sendo visíveis todos os tipos de células secretoras - células mucosas dos tipos I (m1) e II (m2) e células serosas dos tipos I (s1), II (s2) e III (s3), além de células basófilas (cb); (6-8) Deroceras laeve: observam-se os abundantes grânulos citoplasmáticos (seta) das células de revestimento de um ducto intralobular (di). Barra: $25 \mu \mathrm{m}$. 
$2 \mu \mathrm{m}$ de espessura foram corados com azul de metileno/fucsina básica (AM/F) (BENNETT et al. 1976). As glândulas salivares foram analisadas principalmente com base no material incluído em histo-resina, por ser esta, dentre as técnicas testadas, a que melhor preservou a estrutura dessas glândulas, possibilitando a observação de detalhes, tais como o aspecto geral do citoplasma, a morfologia dos grânulos secretores ou a presença de secreção amorfa, bem como a diferenciação de estruturas como microvilos e cílios, dentre outras.

\section{RESULTADOS}

O parênquima das glândulas salivares das espécies estudadas é composto, em B. pallens, L. marginata e D. reticulatum, por cinco tipos de células secretoras, enquanto em $D$. laeve, $D$. rodnae e M. tenellus identificam-se apenas quatro tipos (Tab. I). As células secretoras possuem um corpo celular, de forma oval a poligonal, e um prolongamento celular estreito, o qual desemboca nos ductos intralobulares. Uma fina camada de tecido conjuntivo frouxo preenche os espaços entre as células que compõem o parênquima glandular.

Dois grupos de células secretoras podem ser diferenciados: células mucosas, cuja secreção apresenta reação positiva para alcian blue e/ou PAS, contendo, portanto, glicosaminoglicanas ou glicoproteína, e células serosas, apresentando reação positiva ao azul de Bromophenol, e algumas também ao tetrazonium, o que indica a presença de secreção proteíca básica. Adicionalmente, há um tipo celular, provavelmente indiferenciado, denominado célula basófila.

As células mucosas do tipo I (Figs 1-5, 8, 9, 11) são as mais abundantes nas glândulas salivares. Apresentam pequenos grânulos secretores basófilos, entre os quais visualiza-se o citoplasma acidófilo (AM/F). Em L. marginata e nas três espécies de Deroceras estudadas, os grânulos são fortemente basófilos, enquanto em B. pallens, M. tenellus e T. budapestensis, fracamente basófilos (azul-claro com AM/F).

As células mucosas do tipo II (Figs 2, 5, 7, 9, 11) são freqüentes e possuem grânulos com uma porção periférica fortemente basófila e porção central fracamente basófila. Assim como as células mucosas do tipo I, seu citoplasma é acidófilo.

As células serosas do tipo I (Figs 1-3, 5, 7, 8, 10,12) são as mais numerosas dentre os tipos de células serosas. Possuem citoplasma basófilo e grânulos secretores de grande diâmetro, especialmente em $D$. laeve, $D$. reticulatum, $D$. rodnae e $M$. tenellus, os quais coram-se geralmente em púrpura (AM/F). Em $M$. tenellus, D. laeve e D. rodnae, a coloração dos grânulos varia de

Tabela I. Dimensões médias $(\mu \mathrm{m})$ do corpo celular, do núcleo e dos grânulos secretores das células das glândulas salivares de espécies de Limacoidea e Milacidae. (CB) célula basófila, (CC) corpo celular, (CM) célula mucosa, (CS) célula serosa, (GS) grânulos secretores, (N) núcleo, (-) provavelmente ausente; (-) grânulos secretores ausentes. Os algarismos romanos indicam os diferentes tipos de células mucosas e serosas.

\begin{tabular}{|c|c|c|c|c|c|c|c|c|}
\hline & & B. pallens & L. marginata & D. laeve & D. reticulatum & D. rodnae & M. tenellus & T. budapestensi \\
\hline & $\mathrm{CC}$ & $23,5 \times 13,5$ & $41,5 \times 26,5$ & $33,0 \times 15,0$ & $38,0 \times 15,0$ & $41,5 \times 23,0$ & $43,0 \times 23,0$ & $23,0 \times 18,0$ \\
\hline \multirow[t]{3}{*}{$\mathrm{CB}$} & $\mathrm{N}$ & $11,5 \times 8,0$ & $13,5 \times 12,0$ & $13,0 \times 9,5$ & $15,5 \times 8,5$ & $12,5 \times 11,0$ & $13,5 \times 10,5$ & $9,0 \times 8,0$ \\
\hline & GS & - & - & - & - & - & - & - \\
\hline & $\mathrm{CC}$ & $65,0 \times 39,3$ & $47,0 \times 23,0$ & $41,0 \times 26,5$ & $43,5 \times 26,5$ & $45,5 \times 25,5$ & $34,0 \times 21,0$ & $53,0 \times 39,0$ \\
\hline \multirow[t]{3}{*}{ CMI } & $\mathrm{N}$ & $12,5 \times 7,0$ & $13,0 \times 10,5$ & $13,0 \times 9,0$ & $13,0 \times 11,5$ & $13,5 \times 7,0$ & $11,0 \times 9,3$ & $14,3 \times 11,5$ \\
\hline & GS & 2,6 & 2,3 & 2,6 & 3,2 & 3,0 & 1,6 & 4,0 \\
\hline & $\mathrm{CC}$ & $46,0 \times 23,5$ & $36,0 \times 21,5$ & $36,5 \times 32,5$ & $35,0 \times 25,5$ & $47,0 \times 34,0$ & $39,0 \times 33,0$ & $31,5 \times 19,5$ \\
\hline \multirow[t]{3}{*}{ CM II } & $\mathrm{N}$ & $8,5 \times 7,5$ & $8,5 \times 8,0$ & $11,0 \times 6,5$ & $8,5 \times 5,5$ & $9,0 \times 7,5$ & $9,5 \times 8,0$ & $11,5 \times 7,0$ \\
\hline & GS & 3,6 & 2,7 & 2,8 & 2,8 & 3,0 & 3,0 & 3,0 \\
\hline & $\mathrm{CC}$ & $53,5 \times 28,5$ & $40,0 \times 26,5$ & $41,0 \times 35,0$ & $36,3 \times 20,3$ & $48,5 \times 39,0$ & $54,0 \times 34,5$ & $28,0 \times 17,5$ \\
\hline \multirow[t]{3}{*}{ CSI } & $N$ & $11,5 \times 7,5$ & $13,0 \times 11,5$ & $13,5 \times 12,5$ & $14,0 \times 9,3$ & $13,5 \times 7,5$ & $13,0 \times 10,0$ & $14,0 \times 9,0$ \\
\hline & GS & 5,3 & 4,0 & 7,6 & 6,4 & 7,0 & 8,0 & 5,0 \\
\hline & $\mathrm{CC}$ & $67,0 \times 50,0$ & $59,5 \times 32,0$ & $28,0 \times 19,0$ & $37,5 \times 17,0$ & $51,5 \times 29,0$ & $33,5 \times 25,0$ & - \\
\hline \multirow[t]{3}{*}{ CS II } & $\mathrm{N}$ & $14,0 \times 8,5$ & $13,5 \times 11,3$ & $9,5 \times 6,0$ & $12,5 \times 8,5$ & $11,5 \times 8,5$ & $13,0 \times 10,5$ & - \\
\hline & GS & 5,6 & 4,0 & 3,6 & 9,0 & 5,0 & 4,5 & - \\
\hline & $\mathrm{CC}$ & $19,5 \times 16,0$ & $30,5 \times 23,0$ & - & $38,0 \times 20,0$ & - & - & $33,0 \times 21,5$ \\
\hline \multirow[t]{2}{*}{ CS III } & $N$ & $9,0 \times 6,5$ & $14,0 \times 5,0$ & - & $10,0 \times 10,0$ & - & - & $11,0 \times 9,0$ \\
\hline & GS & -- & -- & & -- & & & -- \\
\hline
\end{tabular}



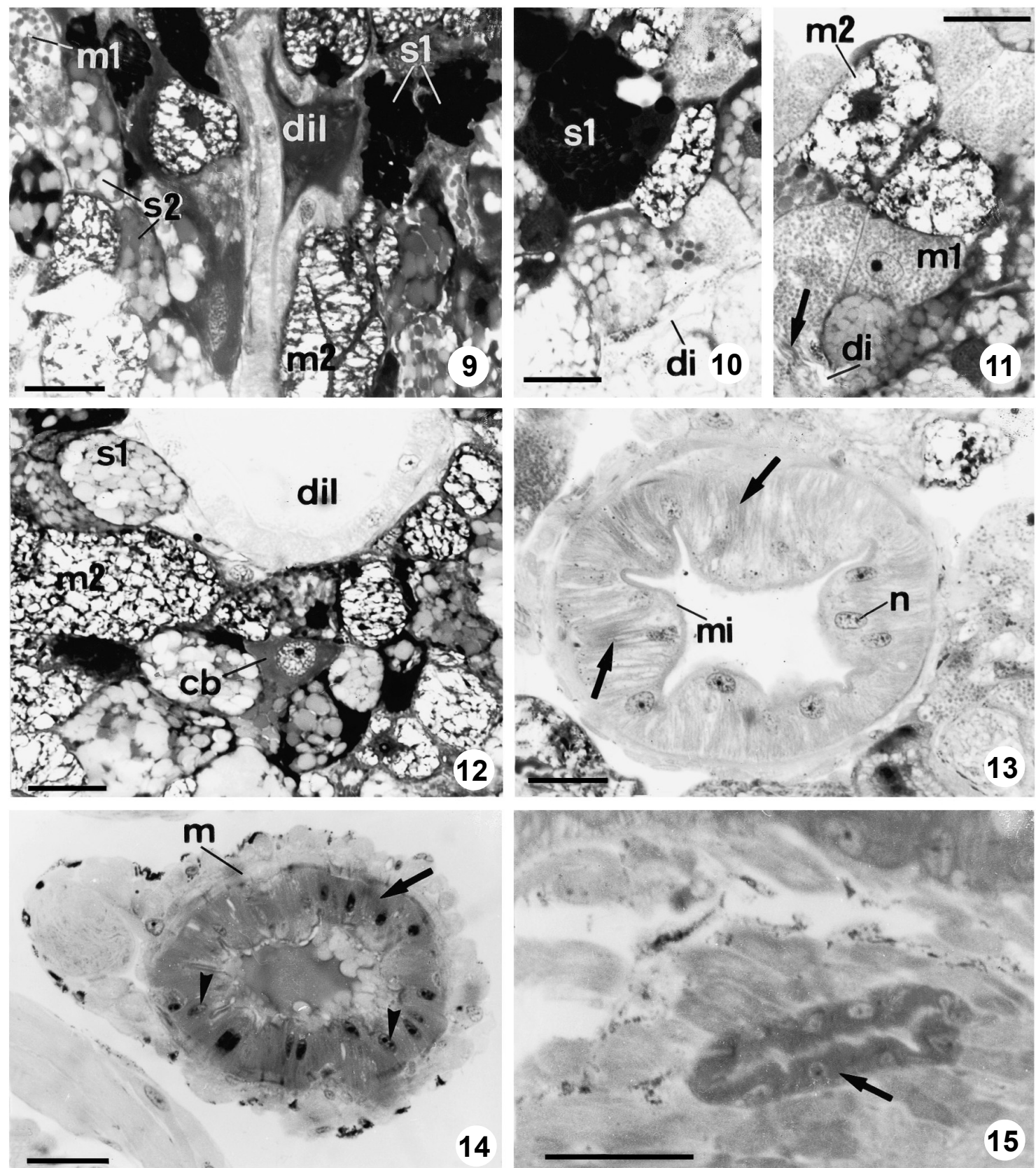

Figuras 9-15. Glândulas salivares em inclusão histo-resina e coloração azul de metileno/fucsina básica. (9) Deroceras reticulatum: observase o epitélio cúbico de um ducto interlobular (dil); (10-11) Malacolimax tenellus, na figura 11, indicam-se os longos cílios (seta) do epitélio de revestimento de um ducto intralobular (di); (12) Deroceras rodnae: observa-se um ducto interlobular (dil) de grande calibre; (13) Malacolimax tenellus: observa-se um ducto interlobular de grande calibre, apresentando estriação no citoplasma basal (setas), núcleos (n) deslocados para a metade apical das células e microvilos (mi); (14) ducto excretor principal de Lehmannia marginata, no percurso entre a glândula salivar e o bulbo bucal: observam-se estriação basal (seta) e os núcleos apicais (cabeças de seta) do epitélio de revestimento, bem como a musculatura subjacente $(\mathrm{m})$; $(15)$ ducto excretor principal de Deroceras laeve, no interior da parede do bulbo bucal, próximo à desembocadura na cavidade desse órgão. Nota-se o epitélio de revestimento, cujas células variam de pavimentosas a cúbicas com citoplasma homogêneo (seta). (cb) Célula basófila, (m1) célula mucosa do tipo I, (m2) célula mucosa do tipo II, (s1) célula serosa do tipo I, (s2) célula serosa do tipo II. Barra: $25 \mu \mathrm{m}$.

Revista Brasileira de Zoologia 20 (3): 401-407, setembro 2003 
Tabela II. Altura média do epitélio de revestimento dos ductos das glândulas salivares de espécies de Limacoidea e Milacidae ( $\mu$ m). (1) externamente ao bulbo bucal; (2) no interior da parede do bulbo bucal.

\begin{tabular}{|c|c|c|c|c|c|c|c|c|}
\hline & & B. pallens & L. marginata & D. laeve & D. reticulatum & D. rodnae & M. tenellus & T. budapestensis \\
\hline \multicolumn{2}{|c|}{ Ductos intralobulares } & 3,8 & 5,0 & 4,7 & 4,3 & 6,3 & 5,5 & 3,5 \\
\hline \multicolumn{2}{|c|}{ Ductos interlobulares } & 10,0 & 11,8 & 12,5 & 8,0 & 12,5 & 14,0 & 6,8 \\
\hline \multirow{2}{*}{ Ductos principais } & (1) & 20,3 & 23,0 & 10,0 & 17,0 & 30,0 & 23,7 & 14,0 \\
\hline & (2) & 6,8 & 8,5 & 3,3 & 8,0 & 8,0 & 7,3 & 8,0 \\
\hline
\end{tabular}

púrpura a rosa, enquanto em $D$. reticulatum, esses grânulos apresentam-se corados mais freqüentemente em azul-escuros ou, mais raramente, em púrpura.

As células serosas do tipo II (Figs 1, 5, 6, 8, 9), pouco numerosas, exceto em L. marginata, apresentam citoplasma basófilo e grânulos secretores corados em rosa (AM/F). Este tipo celular apresenta-se raro em $D$. laeve e não foi observado em $T$. budapestensis.

As células serosas do tipo III (Figs 2, 4, 5) são raras, não tendo sido observadas em $D$. laeve, D. rodnae e M. tenellus. Em D. reticulatum e T. budapestensis, no entanto, esse tipo celular é relativamente mais freqüente, em comparação com as outras espécies estudadas. São facilmente identificadas por apresentarem secreção amorfa fortemente acidófila (corada em rosaescuro com AM/F), ocupando a maior parte do volume celular. O citoplasma basófilo e o núcleo oval encontram-se na região periférica da célula.

As células basófilas (Figs 5, 6, 12) são pouco numerosas. Possuem citoplasma fortemente basófilo, com núcleo algo excêntrico. Às vezes, observam-se alguns grânulos secretores dispersos no citoplasma.

Três tipos de ductos podem ser diferenciados nas glândulas salivares dos Limacoidea e Milacidae: ductos intralobulares, ductos interlobulares e ductos principais.

Os ductos intralobulares (Figs 6, 8, 10,11) são revestidos por epitélio plano a cúbico simples (Tab. II), com longos cílios. Suas células possuem núcleo fusiforme a esférico e citoplasma com numerosos grânulos diminutos e fortemente acidófilos (Figs 6, 8).

Os ductos interlobulares (Figs 9, 12,13) apresentam maior diâmetro do que os intralobulares e são revestidos por epitélio cúbico simples (Tab. II) contendo microvilos. Possuem núcleo esférico a oval. Distalmente suas células de revestimento podem apresentar características similares às do epitélio de revestimento dos ductos excretores principais. Algumas células mucosas das glândulas salivares desembocam nestes ductos. Sob o epitélio de revestimento dos ductos interlobulares ocorre uma camada fina de tecido conjuntivo frouxo, a qual contém nos segmentos distais desses ductos fibras musculares esparsas.

Os ductos principais (Figs 14, 15) partem das glândulas salivares, dirigem-se anteriormente, lateralmente ao esôfago, e penetram na parede dorsal e posterior do bulbo bucal, atravessando a musculatura desse órgão para desembocar dorsalmente na sua cavidade geral, ao nível da região do odontóforo, na sua porção posterior (LEAL-ZANCHET 1998, 2001). No seu percurso livre, entre a glândula salivar e o bulbo bucal (Fig. 14), esses ductos são revestidos por epitélio cúbico simples (Tab. II) contendo microvilos. Suas células possuem característica estriação no citoplasma basal, enquanto o núcleo localiza-se na metade apical da célula. Subepitelialmente ocorrem tecido conjuntivo frouxo e fibras musculares. A altura do epitélio de revestimento dos ductos excretores principais diminui na direção do bulbo bucal. No seu percurso no interior da parede do bulbo bucal, esses ductos são revestidos por epitélio plano a cúbico simples (Fig. 15, Tab. I), cujas células possuem citoplasma homogêneo, sem qualquer estriação, e núcleo fusiforme.

\section{DISCUSSÃO}

As características gerais das glândulas salivares, no que se refere à constituição do parênquima glandular e dos ductos, são similares nas diferentes espécies de pulmonados, havendo, no entanto, pouca clareza sobre o número de tipos celulares secretores presentes em diferentes espécies. Em parte, isso pode estar relacionado com o fato de que em geral os estudos sobre as glândulas salivares têm sido realizados, por cada autor, em espécies isoladas, em vez de serem estudadas diversas espécies de uma mesma família.

A ocorrência de dois grandes grupos de células secretoras observadas no presente trabalho, para os Limacoidea e Milacidae, concordam com os resultados encontrados para Limax maximus e Arion ater, respectivamente, por BeLTz \& GELPERIN (1979) e MoYa et al. (1992).

Dois tipos de células secretoras mucosas, similarmente ao observado para os Limacoidea e Milacidae, foram também diferenciadas por Boer et al. (1967), WALKER (1970), Beltz \& Gelperin (1979), Moreno et al. (1982) e Charrier (1988).

As células serosas são mais dificilmente comparáveis com as descritas por outros autores, excetuando-se as aqui denominadas células serosas do tipo III, pelas suas características peculiares. Esse tipo celular corresponde às "cellules cystiques" descritas por Blain (1957), BANI (1964) e Charrier (1988), bem como às células císticas de $P$. soleiformis (LEAL-ZANCHET et al. 1991) e "cells with an acidophilic inclusion" (BoER et al. 1967).

Pelas suas características gerais, as células serosas do tipo I das espécies estudadas no presente trabalho correspondem provavelmente às "grain cells" descritas por BoER et al. (1967) e WALKer (1970), assim como às "cell type III" de Beltz \& GelPERIN (1979) e "type P2 cells" de Moya et al. (1992).

As células serosas do tipo II do presente trabalho devem corresponder às "pseudochromosomic cells" de Boer et al. (1967), Walker (1970) e MoRENo et al. (1982), bem como às "type P1 cells" de Moya et al. (1992).

Células basófilas similares às aqui descritas são também diferenciadas por Blain (1957), Boer et al. (1967) e CHARrier (1988). Pelas características histológicas e ultraestruturais que 
apresentam, essas células provavelmente correspondem a células indiferenciadas (BOER et al. 1967). O termo células basófilas foi também utilizado para designar um tipo de célula secretora em P. soleiformis por LEAL-ZANCHET et al. (1991), o qual, porém, não corresponde às células basófilas das espécies estudadas no presente trabalho.

Walker (1970) descreve "Leydig cells" como um tipo de célula secretora das glândulas salivares de D. reticulatum. Este tipo de célula é, no entanto, bem conhecido como um tipo de célula do tecido conjuntivo dos Limacoidea, sendo recomendável evitar-se a mesma denominação para uma célula secretora da glândula salivar. Este mesmo autor descreveu, para as glândulas salivares de $D$. reticulatum, tipos celulares, de ocorrência rara, denominados "mixed cells I e II" e " $\alpha$ e $\beta$ cells", as quais não puderam ser identificadas na presente investigação.

As células presentes nos ductos intralobulares que contêm grânulos acidófilos, conforme descritas no presente trabalho, correspondem às "granular cells" de BoER et al. (1967) e WALKER (1970), bem como às "cell type IV" de Beltz \& Gelperin (1979). Ao contrário das observações realizadas por WALKer (1970) para D. reticulatum, este tipo celular não foi observado nos ductos interlobulares das espécies aqui estudadas. Em relação às demais características dos diversos ductos ocorrentes nas glândulas salivares dos Limacoidea e Milacidae, as observações aqui descritas concordam com as descrições de WALKer (1970), Quattrini (1967) e Leal-Zanchet et al. (1991). As células do epitélio de revestimento dos ductos principais apresentam características de células que realizam transporte de íons, similarmente ao indicado por WALKER (1970) \& QUATTRINI (1967), devendo atuar na absorção de íons das secreções salivares. Não observam-se cílios no epitélio desses ductos, nem nos ductos interlobulares, mas apenas nos intralobulares. A presença dessas estruturas nos ductos intralobulares, e não nos demais tipos de ductos, deve estar relacionada com a ausência de fibras musculares na parede desses ductos, sendo os cílios necessários à movimentação da secreção. Nos ductos interlobulares e principais essa função passa a ser exercida pelas fibras musculares subjacentes.

Sobre a fisiologia das glândulas salivares, RunHAM (1975) comenta as possíveis funções desempenhadas pela saliva, nos pulmonados, a saber: lubrificação durante o processo de ingestão de alimento, retirada de resíduos alimentares da rádula e auxílio na passagem do bolo alimentar para o esôfago. Para os Limacoidea e Milacidae aqui estudados, é importante salientar que não ocorrem células mucosas no bulbo bucal (LEALZANCHET 2001). Adicionalmente, enzimas como amilase e tripsina foram identificadas na saliva de Helix pomatia e Deroceras reticulatum (GUARDABASSI \& FerReRI 1954, WALKER 1970), indicando a atuação da saliva também na digestão extracelular do alimento ingerido.

\section{AGRADECIMENTOS}

Ao CNPq, pelo apoio financeiro (proc. $n^{\circ} 204209 / 90.0$ ). Aos professores Dr. Dieter Bunke e Dr. Wolfgang Rähle, pelas sugestões realizadas ao longo do desenvolvimento desse trabalho, e ao Prof. Dr. Wolfgang Maier, por possibilitar a utilização das instalações do Lehrstuhl Spezielle Zoologie, Universidade de Tübingen, Alemanha. Ao Dr. João Carlos Brahm Cousin pelas sugestões realizadas em uma versão preliminar do manuscrito. Às laboratoristas Martina Hohloch e Teresinha Hensel Oliveira, pelo auxílio na confecção das fotografias.

\section{REFERÊNCIAS BIBLIOGRÁFICAS}

BANI, G. 1964. Osservazione sulle ghiandole salivari di Eobania vermiculata (Müller) (Gasteropodo, Polmonato). Monitore Zoologico Italiano, Firenze, 72 (1-2): 65-88.

Beltz, B. \& A. Gelperin. 1979. An ultrastructural analysis of the salivary system of the terrestrial mollusc, Limax maximus. Tissue \& Cell, Edinburgh, 11 (1): 31-50.

BennetT, H.S.; A.D. Wyrick; S.W. Lee \& J.H. McNeIl. 1976. Science and art preparing tissues embedded in plastic for light microscopy, with special reference to glycol methacrylate, glass knives and simple stains. Stain Technology, Baltimore, 51 (2): 71-97.

Blain, M. 1957. Contribution a l'histophysiologie de la glande salivaire chez l'escargot (Helix aspersa Müller). Archives D' Anatomie Microscopique et de Morphologie Experimentale, Paris, 46 (4): 489-502.

Boer, H.H.; S.E.W. Bonga \& N. Rooyen. 1967. Light and electron microscopical investigations on the salivary glands of Lymnaea stagnalis L. Zeitschrift für Zellforschung, Berlin, 76: 228-247.

Charrier, M. 1988. Structure des glandes salivaires d'Helix aspersa Müller (Mollusque Gastéropode Pulmoné). Haliotis, Paris, 18: 171-183.

Guardabassi, A. \& E. FerReri. 1954. Istofisiologia dell'apparato digerente di Helix pomatia. Archivo Zoologico Italiano, Turin, 38: 61-156.

Hyman, L.H. 1967. The invertebrates. New York, McGraw-Hill, vol. 6, p. 569-573.

LEAL-ZANCHET, A.M. 1998. Comparative studies on the anatomy and histology of the alimentary canal of the Limacoidea and Milacidae (Pulmonata: Stylommatophora). Malacologia, Berkeley, 39 (1-2): 39-57.

. 2001. Microanatomia e Histologia do Bulbo Bucal dos Limacoidea e Milacidae (Mollusca, Gastropoda, Pulmonata). Acta Biologica Leopoldensia, São Leopoldo, 23: 7-23.

Leal-Zanchet, A.M.; J.W. Thomé \& J. Hauser. 1991. Microanatomia e histologia do sistema digestivo de Phyllocaulis soleiformis (Mollusca; Gastropoda; Veronicellidae). IV. Glândula salivar. Comunicações do Museu de Ciências da PUCRS, Sér. Zool., Porto Alegre, 4 (2): 16-27.

Luchtel, D.; A.W.Martin; I. Deyrup-olsen \& H.H. Boer. 1997. Gastropoda: Pulmonata, p. 545-591. In: F.W. HARRISON \& A.J. KoHN (Ed.). Microscopic anatomy of invertebrates. New York, John Wiley \& Sons, vol. 6B, 828p.

Moreno; F.J., J. Pinero; J. Hidalgo; P. Navas; J. Aijón \& J.L. LopésCAMPOS. 1982. Histochemical and ultrastructural studies on the salivary glands of Helix aspersa (Mollusca). Journal of Zoology, London, 196: 343-354.

Moya, J.; M.T. Serrano \& E. Ângulo. 1992. Ultrastructure of the salivary glands of Arion ater (Gastropoda, Pulmonata). Biological Structures and Morphogenesis, Paris, 4 (3): 8187.

Pearse, A.G.E. 1968. Histochemistry theoretical and applied. London, J. \& A. Churchill Ltd., vol. 1, 759p. 
QuatTRINI, D. 1967. Osservazioni sulla ultrastruttura dei dotti escretori delle ghiandole salivari di Helix aspersa Müller (Mollusca Gastropoda Pulmonata). Caryologia, Firenze, 20 (2): 191-206.

RomeIs, B. 1989. Mikroskopische Technik. München, Urban \& Schwarzenberg, 697p.
Runham, N.W. 1975. Alimentary canal, p. 53-104. In: V. FretTer \& J. Peake (Eds) Pulmonates. Functional Anatomy and Physiology. London, Academic Press, vol. 1, 417p.

W ALKER, G. 1970. Light and electron microscope investigations on the salivary glands of the slug, Agriolimax reticulatus (Müller). Protoplasma, Wien, 71: 111-126.

Recebido em 09.I.2003; aceito em 11.VIII.2003. 